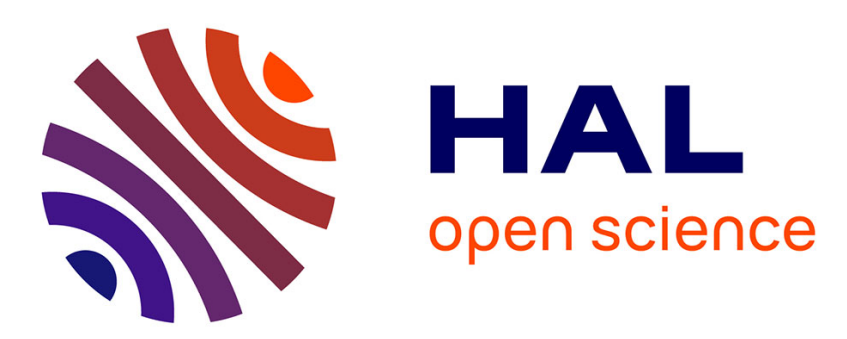

\title{
Control regio de la violencia nobiliaria. La caballería según Alfonso X de Castilla (comentario al título XXI de la Segunda partida)
}

Georges Martin

\section{- To cite this version:}

Georges Martin. Control regio de la violencia nobiliaria. La caballería según Alfonso X de Castilla (comentario al título XXI de la Segunda partida). Isabel ALFONSO, Julio ESCALONA et Georges MARTIN. Lucha política: condena y legitimación en la España medieval, ENS-Editions, pp.219-234, 2004, Annexes des Cahiers de linguistique et de civilisation hispaniques médiévales. halshs-00116339

\section{HAL Id: halshs-00116339 \\ https://shs.hal.science/halshs-00116339}

Submitted on 26 Nov 2006

HAL is a multi-disciplinary open access archive for the deposit and dissemination of scientific research documents, whether they are published or not. The documents may come from teaching and research institutions in France or abroad, or from public or private research centers.
L'archive ouverte pluridisciplinaire HAL, est destinée au dépôt et à la diffusion de documents scientifiques de niveau recherche, publiés ou non, émanant des établissements d'enseignement et de recherche français ou étrangers, des laboratoires publics ou privés. 


\title{
Control regio de la violencia nobiliaria. La caballería según Alfonso X de Castilla (comentario al título XXI de la Segunda partida)
}

\author{
Georges MARTIN \\ École normale supérieure Lettres et Sciences humaines, Lyon \\ SIREM (GDR 2378, CNRS)
}

\begin{abstract}
Alphonse X sube al trono de Castilla y León en 1252. En 1282, dos años antes de su muerte, lo barre una tormenta política que, iniciada en torno a 1270 con las primeras defecciones de los grandes linajes, acabará reuniendo en contra de él la mayor parte de la nobleza, de la Iglesia y de las ciudades. Una de las razones del alzamiento, sin duda la más déterminante, fue la legislación que el rey Sabio pretendió imponer en los primeros años de su reinado y de la que las Siete partidas, cuya primera redacción se lleva a cabo en los años 1256-1265, después de que hubieran solicitado a Alfonso para la elección imperial, constituye la expresión más acabada. Las Siete partidas forman, unos treinta años después del Liber augustalis promulgado por Federico II, la segunda, pero sobre todo la más imponente codificación de derecho real del Medievo central. El libro, destinado a hechar los fundamentos de un Estado monárquico, asocia prescripciones legislativas y consideraciones de orden social y político. Su segunda parte o Segunda partida está dedicada a describir y ordenar la sociedad de los laicos. El título XXI declara tratar de los caballeros ${ }^{1}$.
\end{abstract}

\section{«Caualleros » $\mathbf{y}$ « fijos dalgo »}

\begin{abstract}
Defensores son vno de los tres estados por que dios quiso que se mantuuiesse el mundo. Ca bien assi commo los que ruegan a dios por el pueblo son dichos oradores e otrosi los que labran la tierra e fazen en ella aquellas cosas por que los omes han de biuir e de mantenerse son dichos labradores, otrosi los que han a defender a todos son dichos defensores ${ }^{2}$.
\end{abstract}

El preámbulo al título XXI de la Segunda partida, que reza « De los caualleros e de las cosas que les conuiene fazer », se abre con la primera manifestación explícita del enunciado trifuncional en Castilla. Que esto ocurra sólo en la Segunda partida (y no en la primera,

\footnotetext{
* Una primera versión francesa de este trabajo está por publicar en el homenaje a Michel Garcia.

${ }^{1}$ Gregorio LÓPEZ, Las siete partidas, Salamanca, 1555; facsímil : 3 vol., Madrid : Boletín Oficial del Estado, 1974. Segunda partida, vol. 1 ; título XXI («De los caualleros e de las cosas que les conuiene fazer »), fol. 70 $\mathrm{r}^{\circ} \mathrm{b}-76 \mathrm{v}^{\circ} \mathrm{b}$ de la Segunda partida.

${ }^{2}$ Ibid., fol. $70 \mathrm{r}^{\circ} \mathrm{b}-70 \mathrm{v}^{\circ} \mathrm{a}$.
} 
dedicada a los « oradores ») y además sólo en su título XXI dice la importancia de concebir a los caballeros en el marco, ya antiguo, de una representación de la sociedad que la divide en tres estados encargado cada uno de una función propia. La equivalencia parece exacta entre « caualleros » $\mathrm{y}$ 《 defensores »:

[Defender e guardar la tierra de los enemigos es cosa que conuiene a todos comunalmente], pero con todo esso, a los que mas pertenesce son los caualleros a quien los antiguos dizen defensores ${ }^{3}$.

Ahora bien, una primera sección de « leyes » (leyes I y II), dedicada a la formación de la « cauallería » y a la semántica de esta palabra ${ }^{4}$, en que el miles es definido etimológicamente como un hombre escogido entre mil y en que se evocan los criterios sucesivamente adoptados para obrar dicha selección, usa de la Epitoma rei militaris, de Vegecio, para exaltar por encima de las dotes físicas (resistencia, fuerza, rapidez) o técnico-profesionales (aguante de los venadores, entrenamiento al « ferir » de carpinteros, herreros y pedreros, impasibilidad de los carniceros ante la matanza), la verecundia de los hombres de buena estirpe -la « verguenza » que tienen « naturalmente » los « omes de buen linaje »- la cual « vieda al cauallero que non fuya de la batalla e por ende [...] le faze vencer $»^{5}$. Alfonso X y sus oficiales van incluso más allá de Vegecio erigiendo el « buen linaje »y, más estrictamente la fidalguía (o nobleza), en criterio supremo («E por esto sobre todas las cosas cataron [los antiguos] que fuesen [los caualleros] omes de buen linaje... », ley II) ${ }^{6}$ y llegando, conforme fluye el discurso, a emplear el término « fijo dalgo » como sinónimo de « cauallero » :

Ley VII. Que los caualleros deben ser bien acostumbrados.

Usando los fijos dalgo de cosas contrarias les faze que lleguen a acabamiento de las buenas costumbres $[\ldots]^{7}$.

Todos sabían que existía en Castilla una potente y numerosa caballería municipal (los famosos « caualleros de las cibdades » ou « cibdadanos ») cuyos miembros, por mucho que ejercieran una función y disfrutaran de franquicias que los asemejaban a la « fidalguía », no

\footnotetext{
${ }^{3}$ Ibid. $70 \mathbf{v}^{\circ} \mathbf{a}$.

${ }^{4}$ Ibid., $70 \mathrm{v}^{\circ} \mathrm{a}-71 \mathrm{r}^{\circ} \mathrm{b}$.

${ }^{5}$ M. NISARD, Ammien Marcellin, Jornandès, Frontin (Les stratagèmes), Végèce, Modestus, avec la traduction en français, publiés sous la direction de..., Paris : J. J. Dubochet Le Chevalier, 1849 p. 659-734. Libro 1, cap. 6 y 7, p. 662a-663a. Concretamente : « Juventus enim, cui defensio provinciarum, cui bellorum committenda fortuna est, et genere, si copia suppetat, et moribus debet excellere. Honestas enim idoneum militem reddit. Verecundia dum prohibet fugere, facitesse victorem ». G. LÓPEZ, 1, fol. 71rª de la Segunda partida.

${ }^{6} \mathrm{LÓPEZ}$, fol. $71 \mathrm{r}^{\circ} \mathrm{a}$.

${ }^{7}$ Ibid., $72 \mathrm{r}^{\circ} \mathrm{b}$.
} 
eran considerados como « fijos dalgo » ${ }^{8}$. Es más : Alphonse X hizo mucho por desarrollar y fortalecer este grupo social ${ }^{9}$. La asimilación de los « caualleros » a los « fijos dalgo » es pues una deliberada distorsión de la realidad.

Un tercer criterio precisa aún más, a partir de la ley XI, la definición del « cauallero ». Expuesto sin preámbulo y como si fuera una necesidad el someterse a dicho ceremonial, el ordenamiento de la investidura caballeresca -Ley XI : "Quien ha poder de fazer -[no caualleros sino]- los caualleros o non ${ }^{10}{ }^{-}$hace a su vez de la investidura una condición necesaria a la existencia del « cauallero ». También se sabía perfectamente que el ejercicio de la caballería, que el gozar del apelativo o título de "cauallero », no implicaba de ningún modo en Castilla que uno hubiera sido solemnemente investido. Muy altos personajes, reyes incluso, no habían sido nunca armados ni se habían preocupado lo mínimo por serlo ${ }^{11}$. Segunda distorsión deliberada de las prácticas en la legislación regia.

Bien se ve lo que motiva una y otra de estas distorsiones. En realidad, el título XXI de la Segunda partida no trata de los « caualleros », sino de los «fijos dalgo », de la nobleza en general, y eso con la intención de encerrar su concepto en una función (la de los « defensores ») y en un rito (el de la investidura caballeresca). Al contrario de lo que escriben comunmente los comentadores, la intención fundamental de Alfonso X no fue reservar a los nobles la investidura caballeresca. Esto iría, por lo demás, en contra de sus prácticas ${ }^{12}$. Lo que intenta conseguir el rey es que la nobleza se amolde al modelo éticosocial de la caballería.

\section{Función}

La concepción funcional de la nobleza como caballería da lugar a consideraciones técnicas. Procedentes de fuentes romanas (Frontino y sobre todo Vegecio, en lo esencial), éstas pueden tocar al conocimiento y cuidado que se debe tener de los caballos y de las armas (ley $\mathrm{X})^{13}$ como también (ley VIII) ${ }^{14}$ a lo oportuno que es asociar en el combate la astucia (« artería ») al buen manejo de las armas (« mañas»). Sin embargo, otras consideraciones afectan más

\footnotetext{
${ }^{8}$ Últimos estudios sobre el tema : José Antonio JARA FUENTE, «La ciudad y la otra caballería : realidad político-social e imaginario de los caballeros ('villanos') » et Manuel GONZÁLEZ JIMÉNEZ, «La caballería popular en la frontera » in: La chevalerie en Castille à la fin du moyen âge. Aspects sociaux, idéologiques et imaginaires, (Georges MARTIN, dir.), París : Ellipses, 2001

${ }^{9}$ Cf. Joseph F. O'CALlAGHAN, El rey sabio. El reinado de Alfonso $X$ de Castilla, (2 ${ }^{\mathrm{a}}$ ed. española), Universidad de Sevilla, 1999, p. 96, 118 y sobre todo 127-130; también Nelly R. PORRO GIRARDI, La investidura de armas en Castilla del rey Sabio a los Católicos, Valladolid: Junta de Castilla y León, 1998, p. 105-106 y 209

${ }^{10} \mathrm{G}$. LÓPEZ, 1, fol. $72 \mathrm{v}{ }^{\circ}$ de la Seguna partida.

${ }^{11} C f$. N. R. PORRO GIRARDI, La investidura de armas..., p. 77-142 y 271-315.

${ }^{12}$ Vid. infra nota 34 y pasaje correspondiente.

${ }^{13}$ G. LÓPEZ, 1, fol. $72 \mathrm{r}^{\circ} \mathrm{b}-\mathrm{v}^{\circ}$ a de la Seguna partida.

${ }^{14}$ Ibid., fol. $72 \mathrm{r}^{\circ}$.
} 
completamente la vida del caballero. Consideraciones dietéticas le indican cómo debe comer, beber y dormir (ley XIX) ${ }^{15}$. Otras prescripciones tocan a la vestimenta -es obligatorio llevar manto y espada (ley XVII) ${ }^{16}$, se aconseja además adoptar colores vivos, reputados conferir valor y alegría (ley XVIII) ${ }^{17}$-, a la buena educación -no hay que pronunciar palabras feas (ley XXII $)^{18}$ - como también a la enseñanza - así como a los monjes se les leía en el refectorio fragmentos de las santas escrituras, conviene que durante las comidas se lea a los caballeros los hechos de armas conservados en las crónicas o que se les cante alguna gesta (ley XX) ${ }^{19}$.

Esta regulación de la vida del caballero, que rige hasta sus afectos -esa « alegría » tan deseable que es casi obligatoria...- aparece como una consecuencia «técnica » de la interpretación funcional de la nobleza y corresponde, por parte de los legistas, a una voluntad de modelización destinada a convertir a este grupo social en una herramienta perfectamente preparada a que la tome en mano un poder deseoso de dominarla y de hacer uso de ella.

Este proceso recibe una expresión particularmente fuerte (de origen platónico) en la ley VII que divide al caballero en dos partes, una « fuerte y brava », dirigida hacia el enemigo, otra «mansa y omildosa » dirigida hacia sus compañeros ${ }^{20}$. En cuanto al poder en beneficio de quien se hace dicha funcionalización, lo vemos aflorar en tal consideración moral en que el enunciado trifuncional da cabida a una entidad que por lo común no contiene :

\footnotetext{
Como quier que todo ome aya voluntad de ser bueno e deua trabajarse de auer [las cuatro virtudes cardinales], tan bien los oradores, que diximos, como los otros que han de gouernar las tierras por sus labores e trabajos, con todo aquesto non ha ningunos a que mas conuenga que a los defensores, porque ellos han a defender la eglesia e los reyes e todos los otros (ley IV) ${ }^{21}$.
}

Notamos, sin embargo, en estas últimas citas, que lo más importante de las consideraciones técnicas es que estén habitadas por una ética. Ésta última alcanza, lo veremos, hasta el mismo linaje del caballero y da lugar a una negociación de valores entre el legislador regio y una nobleza que es la cosa de la que trata pero también el grupo social al que principalmente se dirige.

\section{Ética}

Cuando los juristas alfonsinos tratan del conocimiento que deben tener los caballeros de

\footnotetext{
${ }^{15}$ Ibid., fol. $74 \mathrm{v}^{\circ} \mathrm{b}-75 \mathrm{r}^{\circ} \mathrm{a}$.

${ }^{16}$ Ibid., fol. $74 \mathrm{r}^{\circ} \mathrm{b}-\mathrm{v}^{\circ} \mathrm{a}$.

${ }^{17} \mathrm{Ibid}$., fol. $74 \mathrm{v}^{\circ}$.

${ }^{18}$ Ibid., fol. $75 \mathrm{v}^{\circ}$.

${ }^{19} \mathrm{Ibid}$., fol. $75 \mathrm{r}^{\circ}$.

${ }^{20}$ Ibid., fol. $72 \mathrm{r}^{\circ} \mathrm{a}$

${ }^{21}$ Ibid., fol. $71 \mathrm{v}^{\circ} \mathbf{a}$.
} 
los caballos y de las armas y de cómo deben cuidar de éstos, sitúan su propósito dentro de la categoría del «saber» que dichos caballeros deben adquirir y este saber, a su vez, lo subordinan a la categoría del «entendimiento » (título de la ley V: «Que los defensores deuen ser entendidos » ${ }^{22}$; título de la ley VI : «Que los caballeros deben ser sabidores para saber obrar de su entendimiento ${ }^{23}$ ). El Setenario, última versión, inconclusa, del prólogo general y de la primera de las Siete partidas ${ }^{24}$, hace de estas dos nociones unos valores intelectuales que, junto con la « razón », que ilumina el « entendimiento », y la « natura », de la cual éste saca un « saber çierto », forman el cuadrángulo epistemológico del racionalismo sobre el que Alfonso X pretendía fundamentar su gobierno ${ }^{25}$. En cuanto a lo que se presenta como una dietética del caballero, constituye de hecho un entrenamiento diario a la « mesura » (o templanza) -como lo indica el título de la ley XIX, que expone dicha dietética (« Como los caualleros deuen ser mesurados $»)^{26}$-, siendo vinculada a su vez esta virtud, ya desde la ley IV, a las demás virtudes cardinales que deben poseer los caballeros (« cordura », « fortaleza » $\mathrm{y}$ « justicia »), virtudes que les recuerda la espada que deben llevar constantemente y en cuyas partes se hallan todas simbolizadas ${ }^{27}$. Del mismo modo, el manto se lleva « por mostrança que los caualleros deuen ser cubiertos de humildad para obedescer sus mayores » (ley XVIII) ${ }^{28}$, mientras que el cuidado en la expresión no sólo excluye las palabras «villanas » (groseras) sino también, dentro de una valoración más ajustada a la ética política, la « desmesura », la « soberuia » y la « mentira » (ley XXII) $)^{29}$.

Esta construcción, que ya de por sí moraliza y pretende sojuzgar a la «caballería » -esto es, lo repito, a la nobleza- sujetándola a los valores ideológicos alfonsinos, se cifra en una virtud de índole política, virtud que exalta la ley IX casi como por casualidad ya que el elogio sobreviene sin aviso, en medio de consideraciones técnicas, entre la ley dedicada a las « mañas » y « artería » (ley VIII) y la ley tocante al conocimiento y cuidado de los caballos y de las armas (ley X). Esta virtud, explícitamente referida a la relación entre el « caballero »y su señor es la « lealtad»:

\footnotetext{
${ }^{22}$ Ibid., fol. $71 \mathrm{v}^{\circ} \mathrm{b}-72 \mathrm{r}^{\circ} \mathrm{a}$.

${ }^{23}$ Ibid., fol. $72 \mathrm{r}^{\circ} \mathrm{a}$.

${ }^{24}$ Sobre este punto, ver mi reciente estudio : «Datation du Septénaire : rappels et nouvelles considérations », Cahiers de linguistique et de civilisation hispaniques médiévales, 24, 2001, p. 325-342.

${ }^{25}$ Kenneth H. VANDERFORD, ed., Alfonso el Sabio. Setenario, $\left(1^{\text {a }}\right.$ ed. Buenos Aires : Instituto de Filología, 1945), $2^{\text {a }}$ ed., reprod. fcs. de la $1^{\text {a }}$ con estudio preliminar de Rafael LAPESA, Barcelona : Crítica, 1984, p. 26-47. La exposición de este modelo épistemológico formará la tercera parte de mi estudio « Alphonse X ou la science politique (Septénaire, 1-11)», cuyas dos primeras partes fueron publicadas en los Cahiers de linguistique hispanique médiévale, 18-19, 1993-1994, p. 79-100 y 20, 1995, p. 7-33.

${ }^{26}$ LÓPEZ, 1 , fol. $74 \mathrm{v}^{\circ} \mathrm{b}$ de la Segunda partida.

${ }^{27}$ Ibid., fol. $71 \mathrm{v}^{\circ}$.

${ }^{28}$ Ibid., fol. $74 \mathrm{v}^{\circ}$.

${ }^{29}$ Ibid., fol. $75 \mathrm{v}^{\circ} \mathrm{b}$.
} 
Ley IX. Como deuen ser los caualleros muy leales.

Leales conuiene que sean en todas guisas los caualleros. Ca esta es bondad en que se acaban e se encierran todas las buenas costumbres e ella es assi como madre de todas. E comoquier que todos los omes la deuen auer, señaladamente conuiene mucho a estos que la ayan, por tres razones segun los antiguos dixeron. La primera es porque son puestos por guarda e defendimiento de todos e non podrian ser buenos guardadores los que leales non fuessen. La segunda por guardar honrra de su linaje lo que non guardarian quando en lealtad errassen. La tercera por non fazer ellos cosa por que cayan en verguença en lo que caerian mas que por otra cosa si leales non fuessen. E por ende ha menester que ayan lealtad en las voluntades e que sepan obrar della. Ca de otra manera, non podria ser que non errassen en ello porque muchas vegadas acaesce que por guardar lealtad a su señor e a aquellos a quien la han de tener fazen tuerto a omes que nunca gelo merescieron e daño a si mismos e a todas las cosas con que han debdo, metiendose a peligro e a muerte e yendo contra sus voluntades dexando todo lo de que aurian sabor, faziendo aquello que non querrian fazer podiendolo escusar. E todo esto fazen por non menguar en su lealtad ${ }^{30}$.

Este conjunto de valores éticos solidarizado por la «lealtad»y vinculado al estado funcional de los defensores encuentra su finalidad en una noción que procede a la vez del universo conceptual de la Política de Aristóteles -la corte de Alfonso X de Castilla parece haber sido el lugar donde se manejó primero la integralidad de esta obra en el curso del medievo- y del derecho romano en que descansaba entonces la construcción de las monarquías. Esta noción remoza la representación tradicional de la trifuncionalidad atrayéndola al campo de la política y eso en el marco de una concepción proto-pública de éste. Se trata del «pro comunal» (el bien común), invocado ya desde la primera ley del título, cuando se da el sentido del latín militia « que quiere tanto decir como compañas de omes duros e fuertes e escogidos para sofrir trabajo e mal, trabajando e lazrando por pro de todos comunalmente ${ }^{31}$ y recordada en una formulación más depurada a continuación de las leyes que establecen el ordenamiento de la investidura caballeresca, al tratar los legistas de la jura que deben hacer entonces los aspirantes a la caballería, la cual consiste en comprometerse a morir si fuese necesario « por su ley » (es decir por su religión), « por su señor [natural] »y « por el pro communal de su tierra » $(\text { ley XXI })^{32}$.

\section{Linaje y honra}

A cambio de esta modelización social y política que la convierte en instrumento de la realeza, la noblezave exaltados dos valores suyos. El primero es el «linaje». No sin duplicidad maneja el legislador regio una noción que contribuye a transferir a la nobleza los contenidos reguladores y sojuzgantes que finge aplicar a la caballería como también a

\footnotetext{
${ }^{30}$ Ibid., fol. $72 \mathrm{r}^{\circ} \mathrm{b}$.

${ }^{31} \mathrm{Ibid}$, fol. $70 \mathrm{v}^{\circ} \mathbf{a}$.

${ }^{32}$ Ibid., fol. $75 \mathrm{r}^{\circ} \mathrm{b}$.
} 
reforzar la responsabilidad de sus miembros, que ya no incumbe sólo a ellos mismos sino que también abarca a sus antepasados (leyes II y IX ${ }^{33}$ ). La exaltación del linaje traduce no obstante la voluntad del rey de congraciarse a los nobles. Así, el linaje está situado en lo más alto de la valoración social, en lo más alto incluso de los valores éticos, garantizando la hegemonía del grupo nobiliario al que se concede que detenta por herencia una calidad a la que otros -prelados, maestros, burgueses ?- acceden difícilmente por el saber y la virtud :

[...] Sobre todas las cosas cataron [los antiguos] que [los caualleros] fuessen omes de buen linaje, porque se guardassen de fazer cosa porque podiessen caer en verguença. E porque estos fueron escogidos de buenos logares e con algo que quiere tanto dezir en lenguaje de España como bien. Por esso los llamaron fijos dalgo, que muestra tanto como fijos de bien. E en algunos otros logares los llamaron gentiles. E tomaron este nome de gentileza, que muestra tanto como nobleza de bondad, porque los gentiles fueron omes nobles e buenos e biuieron mas ordenadamente que las otras gentes. E esta gentileza auian en tres maneras. La vna por linaje. La otra por saber. La tercera por bondad de costumbres e de maneras. E comoquier que estos que lo ganan por sabiduria e por su bondad son por derecho llamados nobles e gentiles, mayormente lo son aquellos que lo han por linaje antiguamente e fazen buena vida porque les viene de lueñe como heredad. $E$ por ende son mas encargados de fazer bien e de guardarse de yerro e de mal estança. Ca non tan solamente quando lo fazen resciben daño e verguença ellos mismos mas aquellos onde ellos vienen. E por ende fijos dalgo deuen ser escogidos [para caballeros] que vengan de derecho linaje de padre e de abuelo fasta en el quarto grado a que llaman bisabuelos. E esto touieron por bien los antiguos porque de aquel tiempo adelante no se pueden acordar los omes. Pero quanto dende en adelante mas de lueñe vienen de buen linaje tanto mas crescen en su honra e en su fidalguia (ley II) ${ }^{34}$.

O también :

Otrosi pusieron [los antiguos] que ninguno non recibiesse honrra de caualleria por precio de auer ni de otra cosa que diesse por ella que fuesse como en manera de compra. Ca bien assi como el linaje non se puede comprar otrosi la honrra que viene por nobleza non la puede la persona auer si ella non fuere atal que la merezca por linaje o por seso o por bondad que aya en si (ley XII) ${ }^{35}$.

No nos dejemos engañar por las últimas frases de la ley II -para el rey Sabio, se trata ante todo de valorar el modelo caballeresco en la opinión de la nobleza ; ya por entonces se había iniciado paulatinamente la investidura de los villanos ${ }^{36}$ - y pasemos, precisamente, a la « honra » que es, para la nobleza, el segundo valor entrañable que exalta el rey y el que menos le escatima. Afirmada desde el preámbulo al título XXI («[defender e guardar la tierra de los enemigos ] es cosa que conuiene a todos comunalmente. Pero con todo esso a los que mas pertenesce son los caualleros [... L Lo vno por que son mas honrados ») ${ }^{37}$, la idea de

\footnotetext{
${ }^{33}$ Ley IX, vid. párrafo anterior. Ley II, vid. infra.

${ }^{34}$ Ibid., fol. $71 \mathrm{r}^{\circ}$.

${ }^{35}$ Ibid., fol. $73 \mathrm{r}^{\circ} \mathrm{b}$.

${ }^{36}$ PORRO GIRARDI, La investidura de armas..., p. 103-106.

${ }^{37}$ LÓPEZ, 1, fol. $70 v^{\circ}$ a de la Segunda partida.
} 
que, entre todos los grupos sociales la caballería es el más honrado corre a lo largo del título. La expresa la semántica de la palabra «cauallería » (ley I : «[...] en España llaman cauallería non por razon que andan caualgando en cauallos mas porque bien assi como los que andan a cauallo van mas honrradamente que en otra bestia, otrosi los que son escogidos para caualleros son mas honrrados que todos los otros defensores $»)^{38}$, como también la etimología de miles (loi II : «Mill es el mas honrrado cuento que puede ser [...] E por esta razon escogian antiguamente de mill omes vno para fazerle cauallero ») ${ }^{39}$, antes que sea desgranada en privilegios en las últimas leyes del título (ley XXIII : « En que manera deuen honrrar los caualleros » y ley XXIV : "Que mejoría han los caualleros apartadamente mas que los otros omes. Conoscidas e apartadas honrras han los caualleros sobre otros omnes... ») $)^{40}$.

Pero aun así, no pasa el rey sin recordar y subrayar las obligaciones que implican estas honras particulares (concretamente en lo tocante a la verguenza y a la lealtad), ni tampoco pierde nunca de vista, en el momento mismo en que proclama las honras debidas a los caballeros, el fortalecimiento del poder regio y el interés general del reino :

Honrrados deuen mucho ser los caualleros, esto por tres razones. La vna por nobleza de su linaje. La otra por su bondad. La tercera por el pro que dellos viene. E por ende los reyes los deuen honrrar como aquellos con quien han de fazer su obra, guardando e honrando a si mesmos con ellos e acrescentando su poder e su honra. $\mathrm{E}$ todos los otros comunalmente los deuen honrrar porque les son assi como escudo e defendimiento e se han de parar a todos los peligros que acaescieren para defenderlos (ley XXIII) ${ }^{41}$.

Volvamos ahora, después de estos comentarios sobre la función y el linaje, a la definición del caballero y a su último componente, la investidura.

\section{Investidura}

El título XXI de la Segunda partida consta de 25 leyes. El primer ordenamiento que se conzaca de la investidura caballeresca en Castilla forma un conjunto homogéneo que ocupa las leyes centrales, XI a XVI, del título.

Hechos non pueden ser los caualleros por mano de ome que cauallero non sea. Ca los sabios antiguos que todas las cosas ordenaron con razon non touieron que era cosa con guisa nin que pudiesse ser con derecho dar vn ome a otro lo que non ouiesse. E bien assi como las ordenes de los oradores non las podria ninguno dar sinon el que las ha, otro tal non ha poder de fazer

\footnotetext{
${ }^{38}$ Ibid., fol. $70 \mathrm{v}^{\circ} \mathrm{b}$.

${ }^{39}$ Ibid., fol. $70 \mathrm{v}^{\circ} \mathrm{b}$.

${ }^{40} \mathrm{Ibid}$., fol. $75 \mathrm{v}^{\circ} \mathrm{b}-76 \mathrm{v}^{\circ} \mathrm{a}$.

${ }^{41}$ Ibid., fol. $75 \mathrm{v}^{\circ} \mathrm{b}$.
} 
ninguno cauallero si non el que lo es. Pero algunos y ouo que touieron que el rey o su fijo el heredero maguer caualleros non fuessen que bien lo pueden fazer por razon del reyno, porque ellos son cabeças de la cauallereia e todo el poder della se encierra en el su mandamiento e por eso lo vsaron e vsan en algunas tierras. Mas segund razon verdadera e derecha ninguno non puede ser cauallero de mano del que lo non fuere. E tanto encarescieron los antiguos la orden de caualleria que touieron que los emperadores ni los reyes non deuen ser consagrados ni coronados fasta que caualleros fuessen. $\mathrm{E}$ aun dixeron mas: que ninguno non puede fazer cauallero a si mismo por honrra que ouiesse. E comoquier que en algunos lugares lo fazen los reyes mas por costumbre que por derecho, con todo esso, non touieron por bien los antiguos que lo fiziessen. Ca dignidad ni orden nin regla non puede ninguno tomar por si si otro non ge la da. $\mathrm{E}$ por ende ha menester que en la caualleria aya dos personas : aquel que la da e el que la rescibe ${ }^{42}$.

La ley XI establece la independencia de la orden de caballería relativamente a la orden de clerecía reservando a los mismos caballeros el derecho de investir, pero también impide el desarrollo anárquico del grupo caballeresco prohibiendo la auto-investidura. En cuanto a los incisos tocantes a las prácticas regias, muchos reyes hasta Alfonso X -también será verdad después de su reinado-, no se habían preocupado de ser armados caballeros ${ }^{43}$ y Fernando III, padre de Alfonso, así como el propio rey Sabio, por razones que aparecerán más lejos y que tenían que ver con su independencia, se habían armado a sí mismos ${ }^{44}$. Y es que la celebración casi sacramental que constituye la investidura repite el sistema en que se apoyaba la concepción funcional de la caballería : un grupo nobiliario homogéneo y aislado que destinan a que lo tome en mano el poder regio. A cambio de esta clausura y de esta dependencia, el rey está dispuesto a renunciar a ciertas prerrogativas consuetudinarias y a dejar que la caballería se acerque a él. Lo que importa es afirmar la necesidad de la investidura y mantener la estructura binaria en la que van a descansar las implicaciones políticas del rito : un donador y un recipiendario, uno que arma otro que es armado.

Enunciadas a continuación de este dispositivo fundamental, las incapacidades jurídicas fijan los límites del grupo representado por los dos actores. Sobre el primero pesan prohibiciones de orden sexual, intelectual y funcional : quedan excluídos las mujeres, los locos (« desmemoriados ») y los clérigos (fin de la ley XI) ${ }^{45}$. El segundo sufre restricciones económicas, físicas, funcionales y éticas : quedan apartados los pobres, los inválidos, los que practican personalmente el comercio, los que armaron a otro « por escarnio » (ley XII) ${ }^{46}$. El

\footnotetext{
${ }^{42} \mathrm{Ibid}$., fol. $72 \mathrm{v}^{\circ}$.

${ }^{43}$ N. R. PORRO GIRARDI, op. cit., p. 271-295. Parece que desde Alfonso el Sabio hasta los Reyes Católicos -a lo largo de más de dos siglos- sólo seis soberanos castellanos hayan sido armados caballeros : Fernando III, Alfonso X, Alfonso XI, Pedro I, Juan I y el regente Fernando de Antequera.

${ }^{44}$ Ibid., p. 277-280. Así lo haría también Juan I, en 1379. Las mismas razones (que aparecerán más lejos) llevaron a Sancho, segundogénito de Alfonso el Sabio, a negarse a que lo armara su hermano mayor Fernando de la Cerda (ibid., p. 275).

${ }^{45}$ LÓPEZ, 1 , fol. $72 \mathrm{v}^{\circ} \mathrm{b}$ de la Segunda partida.

${ }^{46}$ Ibid., fol. $73 \mathrm{r}^{\circ}$.
} 
conjunto de dichas disposiciones tiene por meta garantizar, en el marco de las mentalidades del Medievo, la dignidad y la funcionalidad del grupo. Sigue la descripción de la ceremonia.

Ésta está precedida por el baño del escudero, llevado a cabo por caballeros que también deben ponerle los mejores vestidos, teniendo por « significança » la limpieza exterior del cuerpo y de la vestidura la pureza interior; al futuro caballero le llevan luego a la iglesia donde velará toda la noche (loi XIII) ${ }^{47}$. En ofrecer a los oficiantes un lugar sagrado se cifra la intervención de la Iglesia en la investidura del caballero. Esta relativa marginación, típicamente alfonsina, también se puede apreciar en que la ética caballeresca no conste de las virtudes teologales como también en que se declare la incapacidad legal de los clérigos a armar los caballeros. Esta incapacidad no tenía (o no había tenido siempre) vigencia allende de los Pirineos, por ejemplo, y cuando afirma Alfonso X que « clérigo nin ome de religion » no «podrian fazer caualleros porque seria cosa muy sin razon de entremeterse de fecho de caualleria aquellos que non ouieren ni han poder de meter y las manos para obrar della » (ley $\mathrm{XI})^{48}$, hace como si desconociese el papel que numerosos obispos desempeñaron en los combates de la Reconquista -algunos no muy remotos y bien conocidos de él, como Rodrigo Jiménez de Rada. El resultado es que todo se realiza, sin más intermediario que una misa matutina apenas aludida, entre el aspirante a la caballería y Dios, a quien el primero debe pedir personalmente el perdón de sus pecados tomando plena conciencia del papel determinante que desempeñará el segundo en el curso de su vida militar : « $\mathrm{E}$ deuesele venir en miente como Dios es poderoso sobre todas cosas e puede mostrar su poder en ellas quando quisiere e señaladamente lo es en fecho de armas » (ley XIII $)^{49}$. La vigilia es pues el momento de la solemnidad en que se afirma la dimensión espiritual de la investidura. Dimensión espiritual más que eclesial : en este momento incluso, la esfera de lo político, dominada por el rey y el « pro comunal », es la que, en último término, goza de la finalidad del rito. En este sentido, el escudero está invitado a una meditación que debe recalcar la gravedad de su compromiso y a la que una jura solemne, vamos a verlo, dará todo su contenido. La gravedad del tono concuerda aquí con el contexto, aun si se puede leer entre líneas lo que podía separar las prescripciones de los comportamientos efectivos :

[...] la vigilia de los caualleros non fue establecida para juegos ni para otras cosas, sinon para rogar a Dios ellos e los otros que y fuessen que los guarde e que los enderesce e aliuie como a omes que entran en carrera de muerte (fin de la ley XIII) ${ }^{50}$.

\footnotetext{
${ }^{47}$ Ibid., fol. $73 \mathrm{r}^{\circ} \mathrm{b}-\mathrm{v}^{\circ} \mathrm{a}$.

${ }^{48}$ Ibid., fol. $72 \mathrm{v}^{\circ} \mathrm{b}$.

${ }^{49}$ Ibid., fol. $73 \mathrm{v}^{\circ} \mathrm{a}$.

${ }^{50} \mathrm{Ibid}$, fol. $73 \mathrm{v}^{\circ} \mathbf{a}$.
} 
La investidura propiamente dicha consta de dos momentos. El primero (ley XIV) ${ }^{51}$, aquel en que arman al caballero, especialmente ciñéndole la espada, es tradicional, aun si la realidad de alguna práctica (la de colocar las espuelas) no la acredita ni la documentación ni la literatura anteriores al reinado de Alfonso X. Al principal protagonista, el que arma, no se le da ningún apelativo que indique su función. Lo que importa ante todo es el compromiso del caballero. Éste debe primero aceptar la orden de caballería y declarar que se conformará a sus reglas. Luego viene lo más importante, la jura :

\begin{abstract}
E desque el espada le ouieren ceñido, deuenla sacar de la vayna e ponergela en la mano diestra e fazerle jurar estas tres cosas. La primera, que non recele de morir por su ley si fuere menester. La segunda por su señor natural. La tercera por su tierra. E quando esto ouiere jurado, deuele dar vna pescoçada por que estas cosas sobredichas le vengan en miente, diziendo que dios le guie al su serviçio e le dexe complir lo que alli le prometio e despues desto hale de besar en señal de fe e de paz e de hermandad que deue ser guardada entre los caualleros. E esso mismo han de fazer todos los caualleros, que fueren en aquel lugar, non tan solamente en aquella sazon mas en todo aquel año do quier que el venga nueuamente. E por esta razon no se han de buscar mal los caualleros vnos a otros a menosde echar en tierra la fe que alli prometieron e desafiandose primeramente segund se muestra do fabla de los desafiamientos (fin de la ley $\mathrm{XIV})^{52}$.
\end{abstract}

La investidura caballeresca pretendía pues ser ocasión, por un lado, de solidarizar y apaciguar a la nobleza, y, por otro lado, de conseguir la sujeción jurada de cada uno de sus miembros a las potencias que la ideología alfonsí daba por «naturales »: Dios (y su « ley ») quien, con el padre genitor, constituía una de las dos instancias procedentes de la « natura », el « señor natural» y la «tierra» que constituían las dos instancias vinculadas a la «naturaleza $»^{53}$. De la primera parte del rito, el que arma no saca pues el principal beneficio. Los efectos del juramento están acaparados por una tutela política impersonal, un sistema que he calificado de protopúblico, $y$, más concretamente, por el señor natural supremo de la « tierra » : el rey.

El segundo momento ritual de la investidura (loi XV) ${ }^{54}$ completa este proceso de confirmación o de adquisición de dependencias u obligaciones por parte del aspirante a la caballería. Este momento, el más novedoso, es muy probablemente una invención de los juristas alfonsinos. Da lugar a que le quiten la espada al novicio, a que le desarmen, y se

\footnotetext{
${ }^{51}$ Ibid., fol. $73 \mathrm{v}^{\circ} \mathrm{a}-74 \mathrm{r}^{\circ} \mathrm{a}$.

${ }^{52}$ Ibid., fol. $73 \mathrm{v}^{\circ} \mathrm{b}-74 \mathrm{r}^{\circ}$ a. Sobre la " pescozada ( un golpe de la mano en la sien, probablemente), ver los comentarios de PORRO GIRARDI, op. cit., p. 154-155.

${ }^{53}$ Sobre este sistema conceptual, ver Georges MARTIN, « Alphonse X ou la science politique (Septénaire, 111) », [deuxième partie : « Le modèle politique »], Cahiers de linguistique hispanique médiévale, 20, 1995, p. 733.

${ }^{54}$ LÓPEZ, 1, fol. $74 r^{\circ}$ a de la Segunda partida.
} 
presenta como el término complementario e indisociable del momento en que le arman. Interpreto este segundo momento del rito dentro de la simbólica correspondiente a lo que nos dice el mismo texto de la doble naturaleza, a la vez agresiva y sumisa, del caballero : su investidura le arma y le desarma. Le arma contra el enemigo y le desarma cara a sus compañeros y a los poderes que deben dominarlo. La importancia de este elemento constitutivo la subraya el hecho de que, entre todos los oficiantes de la investidura, aquel que quita la espada al caballero novel es el único que merece una denominación. Es el « padrino » y su papel, cobrando espiritualidad, es asimilado al del padrino de bautismo :

E a este que le desciñe el espada llaman padrino. Ca bien assi como los padrinos al baptismo ayudan a confirmar e a otorgar a su fijado como sea christiano otrosi el que es padrino del cauallero nouel desciñendole el espada con su mano otorga e confirma la caualleria que ha recebido (fin de la ley $\mathrm{XV})^{55}$.

En cuanto a la vinculación política que se trama de en este acto, ésta pertenece a la otra gran categoría de las dependencias y obligaciones practicadas en Castilla durante la Edad Media: la dependencia personal o vasallática ${ }^{56}$. Aquí, en efecto, no son ya entidades «naturales» (nativas, necesarias e impersonales), las que intervienen, sino hombres, personas, a las cuales el aspirante a la caballería puede escoger libremente :

\begin{abstract}
Desceñir el espada $[\ldots]$ non deue ser fecho sinon por mano de ome que aya en si alguna de estas tres cosas : o que sea su señor natural, que lo faga por el debdo que han de consuno; o ome honrrado que lo fiziesse por sabor que ouiesse de fazerle honrra ; o cauallero que fuesse muy bueno de armas que lo fiziesse por su bondad (ley XV) ${ }^{57}$.
\end{abstract}

Caballero famoso, prócer o señor «natural »-al que, aquí como en otros muchos lugares del texto, se le concede la primacía sobre todos los demás-, son personas, movidas por razones variadas y singulares, a las que puede solicitar el escudero para ser armado por ellas, incluso el señor natural, acerca de quien el aspirante puede contractar libremente, además de la dependencia natural que le liga a él necesariamente, una dependencia -y en este caso, mejor dicho, una obligación- personal. La cuestión era delicada, desde luego, pues las prescripciones de una y otra dependencia, de una y otra obligación, podían competir. Para evitar dicho conflicto, sin duda, se las asoció en el rito de investidura : muy difícil se le haría al caballero novel escoger a un padrino que fuese enemigo del señor natural al que acababa

\footnotetext{
${ }^{55}$ Ibid., fol. $74 \mathrm{r}^{\circ} \mathrm{a}$.

${ }^{56}$ Los dos regímenes (natural y vasallático) de la dependencia están expuestos en los títulos XXIV y XXV de la Cuarta partida (LÓPEZ, vol. 2, fol. $60 \mathrm{r}^{\circ}$ sq. de la Cuarta partida).

${ }^{57}$ LÓPEZ, 1, fol. $74 r^{\circ}$ a de la Segunda partida.
} 
de jurar fidelidad. Aun así, los legistas alfonsinos avisan claramente al futuro caballero : « ha de ser muy catado quien es el que [le] ha de desceñir [la espada] », declaran en la ley $\mathrm{XV}^{58}$, y al final de la ley XVI escriben :

[...] los caualleros noueles, pues tan grand debdo han con los que les desciñen las espadas, deuen catar ante que el fecho venga quien son aquellos a quien han de rogar que sean sus padrinos para desceñirgelas ${ }^{59}$.

El « debdo » contraído es, en efecto, muy grande ya que, descartando cualquier acto que fuera en contra de su señor natural, de sus parientes más cercanos o de aquellos con quienes él mismo o su padre hubiera pactado amistad ${ }^{60}$, el nuevo caballero no sólo debe « honrrar », sino también « obedescer » a su « padrino ». Esta obligación -la ley XVI lo declara como a contratiempo- se extiende al que lo ha armado $^{61}$, lo cual tiene por consecuencia de colocar al caballero novel bajo la más completa tutela de las dependencias : la dependencia natural simplificando: Dios, el rey, el reino- y la dependencia u obligación personal, contraída acerca del que le arma y del «padrino ». Reduplicación de los vínculos de dependencia : naturales y personales y dentro de la segunda categoría, relativamente al que le arma y al que le desciñe la espada. Por todos los lados, el rito de la investidura caballeresca pretende sujetar al « fijo dalgo » y trabar su violencia potencial.

El título XXI de la Segunda partida concluye sobre tres leyes de las que las dos primeras aparentan recordar las honras debidas a los « caballeros ».

\section{Honras y castigos}

Pero es el caso que estas leyes tampoco están faltas de ambiguedad y que también las marca la firme voluntad del poder regio de limitar las prerrogativas nobiliarias. Según la ley $\mathrm{XXIII}^{62}$, nadie puede colocarse delante de los caballeros en la iglesia ; pero enseguida se menciona la excepción de « los reyes o los grandes señores a quien ellos [han] de obedescer e de seruir ». El domicilio de los caballeros es inviolable; pero esta inviolabilidad puede levantarla «mandado del rey » o « de justicia ». No se pueden embargar los muebles de un

\footnotetext{
${ }^{58} \mathrm{Ibid}$. fol. $74 \mathrm{r}^{\circ} \mathrm{a}$.

${ }^{59} \mathrm{Ibid}$., fol. $74 \mathrm{r}^{\circ} \mathrm{b}$.

${ }^{60}$ Sobre la amistad como noción política, ver G. MARTIN, « Alphonse X ou la science politique... », p. 29-33, así como Carlos $\mathrm{HEUSCH}$, «Les fondements juridiques de l'amitié à travers les Partidas d'Alphonse $\mathrm{X}$ et le droit médiéval », Cahiers de linguistique hispanique médiévale, 18-19, 1993-1994, p. 5-48.

${ }^{61}$ LÓPEZ, 1, fol. $74 \mathrm{r}^{\circ}$ a de la Segunda partida : «Debdo han los caualleros noueles non tan solamente con aquellos que los fazen, mas aun con aquellos padrinos que les desciñen las espadas. Ca bien assi como son tenudos de obedescer e de honrar a los que les dan la orden de caualleria, otrosi lo han de fazer a los padrinos que son confirmadores della ».

${ }^{62}$ Ibid., 1 , fol. $75 \mathrm{v}^{\circ} \mathrm{b}-76 \mathrm{r}^{\circ} \mathrm{a}$.
} 
caballero estando él presente... a menos que se le ponga plazo para que salga de su casa. El recuerdo de todas estas restricciones me parece más importante que la exaltación, un tanto pomposa, de la «humillación » debida a los caballeros cuando se les saluda o la posición (bien teórica) en que se encontrarían, una vez armados, de poder ser reyes o emperadores (fín de la ley XXIII).

La ley $\mathrm{XXIV}^{63}$, cuyo título anuncia que se va a exponer en ella la « mejoría » que tienen los caballeros sobre los demás hombres, estipula, es verdad, capacidades excepcionales en materia de recursos jurídicos, de plazos, de testamentos y de inmunidad frente al tormento. Pero, a parte de que se recuerda que ésta última sufre la excepción del caso de traición hecha al rey « cuyo natural o vasallo fuesse » o al reino, son sobre todo, y en el mismo marco de la traición hecha al rey, los privilegios en la aplicación de la pena de muerte los que se exponen y con un encarecimiento en la crueldad que deja perplejo en cuanto a la intención verdadera de los autores :

\begin{abstract}
E aun dezimos que maguer le fuesse prouado que non le deuen dar abiltada muerte, assi como rastrandole o enforcandole o destorpandole, mas hanle de descabeçar por derecho o matalle de fambre quando quisiessen mostrar contra el gran crueza por algund mal que ouiesse fecho. E aun tanto touieron los antiguos de España que fazian mal los caualleros de se meter a furtar o a robar lo ageno o fazer aleve o traycion, que son fechos que fazen los omes viles de coraçon e de bondad, que mandaron que los despeñassen de lugar alto por que se desmembrassen o los afogassen en la mar o en otras aguas por que non paresciessen o los diessen a comer a las bestias fieras ${ }^{64}$.
\end{abstract}

La ley $\mathrm{XXV}^{65}$, por fin, cierra el título con un último ceremonial: aquel por el que « pierden los caualleros honra de cauallería». Esta pérdida puede ser simple, y es entonces debida a delitos tocantes al no respeto de las principales prohibiciones funcionales : vender, jugarse o prendar su caballo y armas, robarlos a sus compañeros, armar caballero a quien no le es permitido, practicar pública y personalmente el comercio u otro oficio manual. Pero la pérdida de la honra se acompaña de la muerte en caso de delito que ataña al señor : huída o no asistencia en la batalla, alevosía, traición. El rito consiste entonces en armar al caballero calzándole las espuelas y ciñéndole la espada y luego en desarmarle cortando correas y cinta. En cierto modo, se trata de la repetición del rito de investidura, cuyo segundo momento se ve así caragado como de una amenazadora prefiguración. Desde luego aquí el desarme es definitivo y el caballero, junto con su dignidad y privilegios, pierde entonces la vida.

\footnotetext{
${ }^{63}$ Ibid., 1, fol. $76 \mathrm{r}^{\circ} \mathrm{a}-\mathrm{v}^{\circ} \mathrm{a}$.

${ }^{64}$ Ibid., 1, fol. $76 \mathrm{r}^{\circ} \mathrm{b}$.

${ }^{65}$ Ibid., 1 , fol. $76 \mathrm{v}^{\circ}$.
} 
Destinado a poner al servicio de la realeza la violencia que la sociedad medieval dejaba en manos de la nobleza laica, principal depositario del armamento del reino, el título XXI de la Segunda partida legitima las prerrogativas y privilegios de dicho grupo social encerrándo a éste en el modelo caballeresco bajo la triple especie de una función, una ética y un rito. La maniobra consta de una negociación en cuanto a dos valores fundamentales -« honra » contra « lealtad »-, de una proposición de consenso en torno a la noción de « pro comunal », de una fuerte amenaza de recurso a la coacción legal. Sin embargo, aun no teniendo en cuenta la realidad de los conflictos de intereses, la construcción ideal y normativa de los legistas alfonsinos, muy desequilibrada, constituye una versión muy severamente monárquica de las relaciones entre corona y nobleza. El criterio linajístico resulta muy valorizado -no se podía hacer mucho menos, tratándose de la nobleza- y se proclama constantemente la honra debida a los «caballeros », pero su exaltación misma se acompaña del recuerdo de las más estrictas obligaciones. Una ética dominada por la lealtad, un rito de investidura que aplasta al caballero bajo los « debdos »y, finalmente, una extraña crueldad en la evocación de los castigos aplicables al que no cumpliera con éstos hacen que no se pueda aceptar lo que proclama el rey a menos de ser de antemano partidario de la consolidación de la monarquía. La Iglesia, completamente excluída del universo de la caballería, los hombres de las ciudades, implícitamente despreciados en sus actividades y apartados de una hidalguía que no se puede comprar, no sacaban ninguna ventaja de estas declaraciones. Así podemos imaginar que el título XXI de la Segunda partida formó parte de las proclamaciones contra las que se alzaron « comunalmente » los tres estados y en las que vieron legitimada su lucha política contra el rey. 